\title{
A mulher negra e a formação em Psicologia. Quais as barreiras existentes?
}

\section{The black woman in Psychology undergraduation. What are the barriers faced?}

\author{
Aline Souza Rosa dos Santos ${ }^{1}$, Solange Aparecida Emílio ${ }^{2}$
}

Resumo

O presente estudo é resultado de uma pesquisa que buscou verificar questões relacionadas à associação entre gênero e raça que podem interferir na formação da mulher negra em Psicologia. Buscou-se encontrar elementos para reflexão sobre possíveis barreiras enfrentadas em sua formação. A referida pesquisa teve, como instrumento de coletas de dados, um questionário e entrevistas semiestruturadas. Em um primeiro momento, foi disponibilizado na internet um questionário on-line respondido por 115 mulheres. Para a segunda etapa da coleta, foram sorteadas dez mulheres que se disponibilizaram no primeiro momento da pesquisa a participar da entrevista semiestruturada de caráter qualitativo. Os dados dos questionários foram analisados de forma quantitativa, com o levantamento das respostas mais prevalentes. Então, foram relidas as entrevistas semiestruturadas, para a identificação de temas emergentes nos relatos. Cada um deles foi destacado para a realização da triangulação com os resultados quantitativos e o embasamento teórico, havendo comparação, também, com estudos anteriores. Este artigo aponta para maior necessidade de discussão sobre o tema, inclusive das relações raciais, para a necessidade de maior representatividade de autores e professores negros nas instituições que ofertam o curso de Psicologia e para a necessidade de um esforço coletivo para a identificação e eliminação das barreiras existentes na formação de mulheres negras em Psicologia.

Palavras-chave: Mulheres negras. Formação em Psicologia. Relações raciais.

\begin{abstract}
The present study is the result of a research that sought to verify whether the association between gender and race can interfere in the Psychology undergraduate of black women. We sought to find elements for reflection on possible barriers faced in their training in Psychology. That research had, as a data collection instrument, a questionnaire, and semi-structured interviews. At first, an online questionnaire answered by 115 women was made available on the internet. For the second stage of the collection, ten women, who made themselves available at the first moment of the research, were randomly selected to participate in the qualitative semi-structured interview. The questionnaire data were analyzed quantitatively, with the survey of the most prevalent responses. Then, semi-structured interviews were reread to identify emerging themes in the reports. Each of them was highlighted for
\end{abstract}

\footnotetext{
${ }^{1}$ Psicóloga pela Universidade Anhembi Morumbi, São Paulo, São Paulo, Brasil.E-mail: aline.srs94@gmail.com

${ }^{2}$ Doutorado em Psicologia Escolar e do Desenvolvimento Humano pela Universidade de São Paulo (USP), São Paulo, São Paulo, Brasil. Professora do Centro Universitário FIEO (UNIFIEO), Osasco, São Paulo, Brasil. E-mail: solange.emilio@terra.com.br
} 
the accomplishment of the triangulation with the quantitative results and the theoretical base, having comparison, also, with previous studies. This article points to a greater need for discussion on the topic, including race relations, the need for greater representation of black authors and teachers in the institutions that offer the Psychology course and the need for a collective effort to identify and eliminate barriers existing in the formation of black women in Psychology.

Keywords: Black women. Psychology undergraduate. Race relations.

\section{Introdução}

Este artigo apresenta os resultados de uma pesquisa que teve seu embrião em um grupo de estudos e práticas de extensão realizado em 2017 por professores e estudantes de Psicologia de uma universidade privada do estado de São Paulo. Na ocasião, parte do grupo buscava identificar as principais dificuldades enfrentadas por estudantes de Psicologia que poderiam interferir no ingresso e na permanência no curso e no acesso à formação profissional de qualidade e que atendesse às necessidades da realidade brasileira.

Considerando a baixa presença de pessoas com deficiências no contexto, o primeiro foco foi entender as possíveis restrições enfrentadas por essas pessoas que as impediam de buscar a formação ou de permanecer no curso de Psicologia. O grupo retomou a Lei Brasileira da Inclusão da Pessoa com Deficiência (BRASIL, 2015), em vigência desde janeiro de 2016, que trazia o conceito de "barreiras" que precisariam ser identificadas e eliminadas, para que fosse possível a participação efetiva das pessoas com deficiências na sociedade. Segundo a descrição contida na referida lei, tais barreiras podem ser urbanísticas, arquitetônicas, nos transportes, nas comunicações e na informação, atitudinais e tecnológicas e são caracterizadas como:

qualquer entrave, obstáculo, atitude ou comportamento que limite ou impeça a participação social da pessoa, bem como o gozo, a fruição e o exercício de seus direitos à acessibilidade, à liberdade de movimento e de expressão, à comunicação, ao acesso à informação, à compreensão, à circulação com segurança, entre outros. (BRASIL, 2015, p. 2).
Uma estudante negra que participava do referido grupo, ao ter contato com a definição ao lado, considerou que o conceito de barreiras poderia ser pensado também em relação a outras condições, partindo de sua própria experiência e dos seus enfrentamentos para conseguir ingressar e se manter no curso de Psicologia. Refletiu sobre o fato de que era vista por muitos a sua volta como uma vencedora, simplesmente por ter a possibilidade de cursar Psicologia. Dentro do próprio grupo de pesquisa era a única mulher negra e foi possível a ela identificar que a baixa presença de mulheres negras era uma regra não somente naquele grupo, mas em sua turma no curso e nas demais das que havia tido notícias. Então, assim como ocorria com as pessoas com deficiência, as pessoas negras também estavam em pequeno número na universidade e poderiam enfrentar entraves ou obstáculos ao acesso e permanência no curso de Psicologia.

Ao buscar referências sobre o assunto, a questão de gênero passou também a se evidenciar (HOLANDA; WELLER, 2014). As barreiras enfrentadas em diferentes âmbitos da vida por homens e mulheres pareciam ser diferentes, assim como são as enfrentadas por pessoas com e sem deficiência e pessoas de diferentes origens étnicas. Nasceu, então, o desejo de realização de um projeto de pesquisa para identificar as possíveis barreiras enfrentadas por mulheres negras na formação em Psicologia.

No presente artigo, as discussões dos resultados da pesquisa foram revisadas e ampliadas e, infelizmente, passados quase dois anos da finalização da pesquisa, parecem ainda muito atuais. Pretende-se, com esta comunicação, proporcionar aos profissionais e estudantes envolvidos com graduações em Psicologia alguns elementos para identificar e dar visibilidade às barreiras na 
graduação de mulheres negras em Psicologia para, quem sabe, mobilizar esforços coletivos em busca da eliminação dessas barreiras.

\section{A entrada na universidade e as perspectivas após a formação}

O ingresso no ensino superior é um momento significativamente importante nas vidas dos indivíduos que pode ser pensado como uma etapa importante na promoção de desenvolvimento da autonomia dos sujeitos e sua preparação para o atendimento às necessidades profissionais e sociais (CASANOVA; POLYDORO, 2010). No caso dos estudantes negros, pode significar também um primeiro passo para a ascensão social (TEIXEIRA, 2003; BRANDÃO, 2004).

Durante a graduação, exige-se que os estudantes adquiram novos modelos de comportamento que sejam apropriados para a universidade, mas é necessário levar em consideração as características com as quais o referido nível educacional é alcançado. Santos e Silva (2011) afirmam que há pesquisadores que compreendem que a evasão do ensino superior simboliza a escassez do preparo anterior dos estudantes para as exigências acadêmicas apontando diversos motivos nos sujeitos que possam levar à desistência do ensino superior, como o sentimento de dúvida quanto ao curso e desengajamento, por exemplo. No entanto, as mesmas autoras destacam que há outros fatores que precisam ser considerados no nosso País, relacionados ao que denominam como "seleção oficiosa" (SANTOS; SILVA, 2011, p. 255). Esta pode ser vinculada à organização dos currículos; aos diferentes valores atribuídos aos diplomas relacionados às instituições e aos cursos; e às exigências dos professores, muitas vezes incompatíveis com as condições concretas dos estudantes, sejam materiais, familiares ou de conhecimentos previamente adquiridos. Considerar estas questões pode ser importante para pensarmos se e de que forma tais barreiras foram transpostas por quem se mantém nos cursos.
No que se refere à graduação em Psicologia, é importante compreender como é significada a formação acadêmica pelos estudantes. É a partir desse saber inicial, amparado pelos mestres e colegas, que o futuro profissional experimenta os primeiros contatos com o saber e o fazer da Psicologia (CARMO, 2011). As opiniões e experiências dos estudantes em relação a sua profissão proporcionam uma reflexão crítica que pode se basear na prática profissional e fornecer elementos para contraposições a dogmatismos, privilegiando os aspectos formativos aos tecnicistas (PIRES, 2008). Portanto, é fundamental para as universidades uma mediação pedagógica que considere como o sujeito constrói seu conhecimento pela interação de ensino-aprendizagem com o outro, não somente com o professor e colegas, mas com a instituição acadêmica de forma geral (CARMO, 2011).

No que diz respeito à formação de mulheres negras na Psicologia, seria interessante verificar em que medida o curso promove uma mediação que respeite a especificidade de sua experiência, considerando os atravessamentos de gênero e étnicoraciais que elas podem enfrentar. As Diretrizes Curriculares Nacionais para os Cursos de Graduação em Psicologia, em vigência até o momento da redação deste artigo (BRASIL, 2011) não trazem qualquer referência à importância da abordagem à temática das questões étnico-raciais e de gênero na formação do psicólogo. E o documento com a revisão das Diretrizes Curriculares Nacionais dos Cursos de Graduação em Psicologia, que estabelece também as normas para o Projeto Pedagógico Complementar para a Formação de Professores de Psicologia (BRASIL, 2020), traz somente duas referências a tais questões, sendo uma vinculada à competência cultural a ser desenvolvida na formação de psicólogo, respeitando as "diversidades de gênero, sociocultural, étnico-racial, religiosa e outras" (BRASIL, 2020, p. 9) e a segunda, como uma competência básica esperada do professor de Psicologia (de nível médio) e prevista somente no projeto pedagógico complementar (que versa sobre a Licenciatura em Psicologia e portanto não é 
considerado para a formação de psicólogo) de: "identificar questões e problemas socioculturais, educacionais e outros com postura investigativa, integrativa e propositiva em face de realidades complexas, a fim de contribuir para a superação de exclusões sociais, étnico-raciais, econômicas, culturais" (BRASIL, 2020, p. 13).

A total ausência da temática nas diretrizes nacionais que ainda estão vigentes e a quase ausência da abordagem no documento mais recente evidencia que a importância atribuída às questões de gênero e étnico raciais na formação do psicólogo dependeu (e seguirá dependendo) dos projetos pedagógicos de cada instituição e dos interesses de coordenadores de curso e professores e alunos envolvidos.

Como agravamento ao ponto acima levantado, temos a percepção da Psicologia como uma profissão elitizada (GIL, 1985; BORSEZI et al, 2008, RIBEIRO; SOLIGO, 2020). Então, é importante também que seja considerada a diferença social e de oportunidades presente entre brancos e negros em nossa sociedade, quando problematizamos as perspectivas de formação das mulheres negras em Psicologia.

Dados recentes confirmam essa ideia. De acordo com discussão exposta no relatório que apresenta uma síntese das políticas de igualdade racial de São Paulo (SÃO PAULO, 2013), se a população negra é a mais pobre, isso se reflete no nível de escolarização (para cada homem negro ou mulher negra com ensino superior completo, existem 3,89 pessoas negras com ensino fundamental completo), as mulheres negras têm uma situação ainda mais complexa. Como exemplo disso, o referido relatório cita que no campo do trabalho os homens negros têm maior presença na faixa de salários entre 1 e 3 salários mínimos mensais, enquanto as mulheres negras têm na faixa de até um salário mínimo mensal.

Dados do Relatório produzido para discutir a questão da igualdade racial em São Paulo (SÃO PAULO, 2014) mostram como essa diferença social também repercute em cargos de chefia e ensino superior, por raça e cargo. Homens negros ou pardos com curso superior completo e ocupando cargos gerenciais ou de chefia têm ganho cerca de $31,5 \%$ inferiores aos dos brancos nas mesmas condições. As mulheres negras ou pardas, com nível superior completo, ocupando cargos gerenciais ou de chefia, por sua vez, têm ganhos em torno de 37,5\% inferiores às das mulheres brancas com as mesmas características de formação e ocupação.

Outro dado importante em relação a esta questão é o divulgado no levantamento de informações sobre a inserção dos psicólogos no mercado de trabalho brasileiro feito pelo DIEESE (DEPARTAMENTO INTERSINDICAL DE ESTATÍSTICA E ESTUDOS SOCIOECONÔMICOS, 2016), segundo o qual o psicólogo negro recebe um valor correspondente a aproximadamente $83 \%$ do recebido pelo psicólogo não negro (respectivamente, $\mathrm{R} \$ 2.921,00$ e $\mathrm{R} \$ 3.514,00)$. Este levantamento recebeu respostas de uma maioria de mulheres (90\%). Então, podemos afirmar que as psicólogas negras, em sua maioria, recebem menos do que as psicólogas brancas.

\section{A mulher negra e psicóloga}

O que é ser mulher? O que é ser mulher e negra? O que é ser uma mulher, negra e formar-se em Psicologia?

O Código de Ética Profissional do Psicólogo (CONSELHO FEDERAL DE PSICOLOGIA, 2005), embora não tenha um capítulo que aborde especificamente a questão da participação das mulheres negras na Psicologia, traz como grande marca o respeito aos direitos humanos, enfatiza a importância da igualdade, da promoção de qualidade de vida de pessoas e das coletividades e da contribuição da área para extinção de formas de discriminação e opressão. Portanto, o aprofundamento da Psicologia em questões raciais e de gênero faz-se necessário na busca de uma sociedade livre de discriminações, violência e exploração.

Em publicação realizada na década de 1980, as psicólogas Moura, Mures, Roland e Alakija relataram no artigo intitulado "Eu, mulher, negra e psicóloga", os desafios existentes em suas 
trajetórias. Temas como racismo, dificuldades no trabalho e discriminações estiveram presentes nas falas delas. A seguir foram destacados alguns trechos desse artigo:

Nossa situação é bastante diferente. Até há pouco tempo o negro era escravo. Sair dessa condição para chegar, por exemplo, a um curso de nível superior, é um caminho muito difícil. (Olga Inácio de Moura).

O que eu tenho vivido não é fácil. Quando comecei com o meu consultório, muitas vezes chegava alguém com uma indicação e vinha procurar a psicóloga. Assim que eu abria a porta, e a pessoa percebia que era eu mesma que ia atendê-la, que eu era a psicóloga, levava aquele susto, ficava com uma expressão de espanto. (Neli Ferreira Mures).

Tenho vivenciado essa situação. No meu primeiro dia de trabalho estávamos eu (33 anos) e uma assistente social (22 anos). Fomos apresentadas a uma médica do Centro de Saúde, e na sequência da conversa a médica perguntou à jovem ‘você é a psicóloga?' Então na cabeça da médica, já houve a inversão, a outra deveria ser a psicóloga e eu, a assistente social. (Edna Maria Santos Roland).

E isto sempre foi algo difícil. Difícil porque escolhi uma profissão, trabalho nela e tento desempenhar da melhor forma possível e, na verdade, eu não sou uma cor. (Gicele Maria de Menezes Alakija). (EU..., 1984, p. 11-15).

É possível verificar, nos trechos acima, como alguns marcadores sociais ligados à imagem da mulher negra acompanharam a trajetória dessas psicólogas e como a cor da pele pôde vir antes da formação e se fez presente na vida das profissionais.

As discriminações de raça e gênero produzem efeitos imbricados, ainda que diversos, promovendo experiências distintas na condição de classe e, no caso, na vigência da pobreza, a influenciar seus preditores e, consequentemente, suas estratégias de superação. Neste sentido, são as mulheres negras que vivenciam estas duas experiências, aquelas sempre identificadas como ocupantes permanentes da hierarquia social (MARIANA et al., 2013).
O racismo tem sua especificidade no gênero feminino. Isso fica explícito nas afirmações de Carneiro (2003, p. 3): sobre a condição de objeto impregnada na identidade da mulher negra: "Ontem, a serviço de frágeis sinhazinhas e de senhores de engenho tarados. Hoje, empregadas domésticas de mulheres liberadas e dondocas, ou de mulatas tipo exportação".

São suficientemente conhecidas as condições históricas nas Américas que construíram a relação de coisificação dos negros em geral e das mulheres negras em particular. Sabemos, também, que em todo esse contexto de conquista e dominação, a apropriação social das mulheres do grupo derrotado é um dos momentos emblemáticos de afirmação de superioridade do vencedor. Carneiro (2003) destaca, por exemplo, a grande exibição e valorização de mulheres brancas e loiras por parte da mídia:

\begin{abstract}
Quando falamos em romper com o mito da rainha do lar, da musa idolatrada dos poetas, de que mulheres estamos falando? As mulheres negras fazem parte de um contingente de mulheres que não são rainhas de nada, que são retratadas como antimusas da sociedade brasileira, porque o modelo estético de mulher é a mulher branca. Quando falamos em garantir as mesmas oportunidades para homens e mulheres no mercado de trabalho, estamos garantindo emprego para que tipo de mulher? Fazemos parte de um contingente de mulheres para as quais os anúncios de emprego destacam a frase: 'Exige-se boa aparência'. (CARNEIRO, 2003, p. 1-2).
\end{abstract}

Assim, sendo o grupo de estudantes negras propenso a essas duas opressões - a de cor e de gênero - qual é o lugar destinado às mulheres negras no que se refere à expressão de suas angústias sejam elas referentes às vivências pessoais, seja pela abordagem desta questão nos cursos?

Consideramos necessária a escuta atenta a esta voz, uma vez que a representatividade de mulheres negras neste espaço acadêmico significaria a parte da efetivação da luta da Psicologia sobre os efeitos das discriminações e preconceitos presentes na nossa sociedade, que sabemos ainda precisam 
de amplas discussões. Aliado a isso, temos o mito da democracia racial (CARNEIRO, 2003), a partir do qual a abordagem de tal assunto pode gerar desconforto, uma vez que, segundo esta autora, até as lutas feministas ignoram o impacto do racismo aliado ao gênero para a mulher negra em nossa sociedade.

\section{Racismo}

De acordo com Munanga (2017), é comum a crença de que o Brasil não seja um país preconceituoso e racista, e que a discriminação sofrida por negros é tida apenas no âmbito econômico, sem ligação alguma com a ideia de superioridade e inferioridade presente nas práticas racistas. $\mathrm{O}$ autor acrescenta ainda que tal afirmativa advém do mito de democracia racial brasileira, que se baseia na ideia da mestiçagem como o embasamento de que com a mistura das raças, o brasileiro nada mais é do que um povo mestiço. Sendo assim, como haveria discriminação racial, se brasileiro é justamente uma mistura?

Quanto ao acesso do negro ao ensino superior, Munanga (2007) defende ainda que mesmo reduzindo a pobreza, que atinge maioritariamente os negros, e melhorando o seu nível educacional, através do seu acesso ao ensino superior pelas políticas de ações afirmativas, isso não garante a superação do racismo. O antropólogo complementa que, mesmo que o ensino público melhorasse o seu nível educacional para competir igualmente com os alunos advindos de escolas particulares, os alunos negros levariam cerca de 32 anos para atingir o mesmo nível educacional dos alunos brancos, ainda que os alunos brancos, durante esse tempo, ficassem "estacionados", esperando a "chegada" dos alunos negros.

Segundo Glass (2012), embora a educação tenha um papel fundamental na construção de uma sociedade antirracista, sua finalidade não é apontar práticas racistas, mas sim permitir que cada pessoa assuma a responsabilidade para a transformação da ordem racial sempre que as identificarem em seu meio social. O propósito em si é construção de uma sociedade na qual o diálogo e a ação racialmente crítica e antirracista façam sentido, porque eles não se referem à culpa, mas a estabelecer respeito, oportunidade igual e uma democracia justa. Ter uma responsabilidade no processo de construção de uma sociedade antirracista, perpassa pelo entendimento de que a construção do racismo atinge a todos nós, nos mais variados âmbitos das relações interpessoais e campos sociais e isso não é diferente no ambiente acadêmico.

Agora, cabe a reflexão sobre as implicações de uma ciência que por vezes se nega a discutir a identidade negra - seja dos estudantes, profissionais ou até mesmo do público-alvo de alguma intervenção psicológica - e que, da mesma forma, nega a discussão do racismo que ela reproduz e perpetua. $\mathrm{O}$ que se propõe aqui, numa das discussões deste artigo, é que o leitor se pergunte o quanto as produções da Psicologia realmente estão dispostas a 'tocar o dedo na ferida' da formação da sociedade brasileira? O quanto, de fato, as instituições de ensino estão dispostas a aceitar a representação que se dê na forma de referências bibliográficas ou por professores negros? A não discussão e o não falar colaboram com a manutenção do que já existe. É no silenciamento que o racismo se fortalece, é no silenciamento que ele se estrutura. Munanga (2003 apud VANNUCHI, 2017) descreve o racismo à brasileira como crime perfeito, pois condiciona o negro à condição de não existência.

Diante do ideal branco, o corpo negro pode ser vivido como uma ferida aberta ou um objeto perseguidor. O crime perfeito se consuma justamente quando o negro busca se branquear, o que, no limite, é a negação de si mesmo. Um desejo que deságua no desejo da própria extinção. (VANNUCHI, 2017, p. 67).

Ainda sobre a condição da pessoa negra em alguns espaços, essa pode ser marcada por um fator primordial nesse processo: ela perceber que naquele ambiente, mais especificamente o acadêmico aqui debatido, se deparar que é a única pessoa negra a frequentar tal lugar. Para Hooks (2019), narrativas e assédios racistas são frequentes, logo, 
a autossegregação ou até mesmo a escolha por se aliar a grupos que apoiam a causa antirracista tende a ser comum para pessoas negras como formas de enfrentamento ao racismo no espaço universitário.

Uma das perguntas a ser respondida neste artigo é sobre como fica isso na formação em uma área que tem como um de seus princípios fundamentais, segundo seu código de ética (CONSELHO FEDERAL DE PSICOLOGIA, 2005, p. 7): “o respeito e a promoção da liberdade, da dignidade, da igualdade e da integridade do ser humano".

\section{Psicologia e relações raciais}

Mais uma vez, a reflexão acerca da Psicologia e das relações raciais gera a dúvida sobre o quanto os princípios da profissão estão sendo seguidos. Em importante material divulgado pelo Conselho Federal de Psicologia (CFP), as Referências Técnicas para a Atuação de Psicólogas/os - Relações Raciais (CONSELHO FEDERAL DE PSICOLOGIA, 2017) os autores afirmam que, hoje em dia, a Psicologia mantém-se ainda conivente com a perpetuação desse olhar, silenciando-se diante das desigualdades políticas, dentre elas, o racismo e o sexismo (CONSELHO FEDERAL DE PSICOLOGIA, 2017). Em outro material também disponibilizado pelo Sistema Conselhos (MÄDER, 2016), o Caderno Psicologia e Relações Étnicoraciais, há o alerta sobre o sofrimento psíquico ocasionado pelo racismo e é discutido em um de seus capítulos como a Psicologia pode contribuir para o enfrentamento do assunto. Para os autores deste documento, a Psicologia como ciência da subjetividade humana em suas diferentes dimensões pode fornecer subsídios consistentes para explicar fenômenos como apatia social, vínculos, desenvolvimento psicossocial e os efeitos psíquicos do racismo nas relações humanas.

Apesar de tais documentos apresentarem um avanço na abordagem ao tema, cabem ainda alguns questionamentos, tais como: quanto a Psicologia vem sendo efetiva em suas ações quanto à temática? Como será que vem ocorrendo a participação de cursos e docentes de Psicologia no que se refere à redução das barreiras à formação de qualidade para a mulher negra? Será que a aplicação de estudos e pesquisas de professores e autores negros vêm sendo utilizada de forma a contribuir para o reconhecimento e legitimação das pessoas negras como agentes de transformação neste campo do saber? E como está a presença da mulher negra como referência enquanto profissional, docente, pesquisadora e autora da ciência psicológica? Espera-se que este trabalho ajude a ampliar a compreensão acerca destas questões.

\section{Método}

$\mathrm{O}$ estudo aqui relatado foi do tipo quantiqualitativo, pois teve uma etapa quantitativa, com coleta de dados por meio de questionários que foram disponibilizados pela internet; e utilizou entrevistas semiestruturadas, para se obter aprofundamento e contato com algumas participantes sorteadas dentre as pessoas respondentes que manifestaram disponibilidade em participar da entrevista.

A entrevista e o questionário foram aplicados a mulheres negras matriculadas em cursos de Psicologia de universidades públicas e privadas. Partimos do conceito de "negro" em acordo com o proposto pelo documento com as referências técnicas para atuação de psicólogas(os) que aborda a questão das relações raciais:

Comumente, considera-se pardo aquele que tem ascendência preta miscigenada com um dos outros grupos raciais, é por isso que o Movimento Negro, pesquisadores da área e institutos de pesquisa, como o Instituto Brasileiro de Geografia e Estatística (IBGE), o Instituto de Pesquisa Econômica Aplicada (IPEA) e a Faculdade Latino Americana de Ciências Sociais (Flacso) Brasil, consideram negro uma categoria política composta por pretos e pardos. [grifos dos autores] (CONSELHO FEDERAL DE PSICOLOGIA, 2017, p. 31).

Desse modo, inserimos esta diferenciação no questionário para a obtenção do perfil das respondentes. Os critérios de inclusão eram ser mulher, negra e estudante de Psicologia de instituições 
públicas ou privadas do País. As participantes poderiam estar em qualquer ano ou semestre do curso. Como critério de exclusão, não poderiam participar da pesquisa estudantes do curso de Psicologia da universidade na qual estudavam e trabalhavam as pesquisadoras.

Foram utilizadas no questionário perguntas fechadas, como por exemplo: "As questões de gênero são/foram debatidas no seu curso?" "Quantas professoras negras lecionam ou lecionaram para você na graduação?" "Você considera a questão racial uma barreira para a formação em psicologia?" Questões como estas serviram de sustentação para as entrevistas semiestruturadas do segundo momento. Os dados dos questionários foram analisados de forma quantitativa, com o levantamento das respostas mais prevalentes. Então, foram relidas as entrevistas semiestruturadas, para a identificação de temas emergentes nos relatos, de acordo com a proposta de análise temática de Minayo (2008). Cada um deles foi destacado para a realização da triangulação com os resultados obtidos nos questionários e entrevistas, que foram comparados e confrontados entre si e com formulações de outros autores para que a ampliação da compreensão do fenômeno estudado (MINAYO, 2008).

Os cuidados éticos para a realização de pesquisas com seres humanos foram tomados em todas as etapas de coleta e análise dos dados, considerando a resolução $n^{\circ} 466$ do Conselho Nacional de Saúde - CNS (BRASIL, 2012). A produção da pesquisa, assim como a coleta de dados e a sua análise foram realizados no período de agosto/2017 a agosto/2018. Os nomes utilizados neste artigo são fictícios a fim de preservar a identidade das participantes, seguindo as diretrizes da resolução anteriormente citada. A coleta teve início somente após a aprovação do projeto pelo Comitê de Ética em Pesquisa da Universidade, sob a autorização do parecer $\mathrm{n}^{\circ} 2.376 .797$ e mediante a assinatura do Termo de Consentimento Livre e Esclarecido (TCLE) pelas participantes.

\section{Resultados e Discussões}

\section{Resultados dos questionários}

No primeiro momento da pesquisa, foi disponibilizado na internet um questionário com perguntas fechadas. O questionário foi iniciado por 125 mulheres, mas dez deles não puderam ser utilizados ou não foram concluídos (três mulheres não se identificaram como negras, pretas, pardas ou afrodescendentes, duas não eram estudantes de psicologia e cinco optaram por não participar da pesquisa). Dessa forma, tivemos 115 participantes cujas respostas ao questionário puderam ser aproveitadas.

$\mathrm{O}$ perfil das respondentes encontra-se no Quadro 1:

Quadro 1 - Perfil das respondentes.

\begin{tabular}{|l|c|c|}
\hline \multicolumn{1}{|c|}{ Pergunta } & Resposta mais prevalente & Porcentagem \\
\hline Como se autodeclara & Preta & $80,90 \%$ \\
\hline Faixa etária & $17-25$ anos & $65,20 \%$ \\
\hline Tipo de universidade & Privada & $53 \%$ \\
\hline Bolsa & Prouni & $18,30 \%$ \\
\hline A instituição possui sistema de cotas raciais & Sim & $70 \%$ \\
\hline Ano de graduação & $5^{\circ}$ & $28 \%$ \\
\hline Renda familiar & 2 a 4 salários mínimos & $47 \%$ \\
\hline
\end{tabular}

Fonte: Autoras. 
Os resultados quanto à representatividade de mulheres negras em sua formação apontam que não foram estudadas autoras negras (64\% das participantes) ou foram estudadas de uma a três autoras negras (27\%). As professoras negras estiveram totalmente ausentes para $58 \%$ das respondentes e $40 \%$ declaram ter entre uma a três professoras negras em sua graduação. Apesar (ou por causa) de terem tido pouco contato com autoras e com professoras negras, $90 \%$ das respondentes consideram a representatividade acadêmica por professoras negras como relevante na formação em Psicologia.

A questão de gênero é considerada importante $(63 \%)$ e foi debatida nos cursos de Psicologia das respondentes (74\%). Também foi debatida na formação a questão racial (63\%). A minoria identifica ter sofrido racismo ou injúria racial no contexto acadêmico (27\%). No entanto, a questão racial é considerada uma barreira para a formação em Psicologia (77\%).

Apesar de não terem tido que trancar o curso em nenhum momento por questões financeiras (89\%), esta é considerada pelas respondentes uma barreira na formação em Psicologia (89\%). A questão financeira como uma barreira enfrentada será discutida mais adiante.

\section{Resultados das entrevistas e discussão}

Foram entrevistadas dez mulheres, que responderam questões ligadas a gênero, raça e classe e como tais temáticas percorreram a formação em Psicologia. A fim de preservar as identidades das participantes serão usados nomes fictícios nos recortes apresentados. A seguir, serão discutidos os temas que se destacaram na triangulação do conteúdo das entrevistas com o resultado do questionário e pela articulação com os autores lidos.

\section{O não pertencimento}

O primeiro ponto a ser destacado é o da percepção do ambiente como não sendo um espaço de pertencimento à mulher negra. É possível observar como este, além de um ambiente produtor de conhecimentos, pode ser responsável por marcar a identidade negra das estudantes. Isso não significa o mero reconhecimento da identidade, mas a explicitação da inadequação desta identidade ao contexto.

Bom... Primeiro quando eu cheguei na formação eu já sabia que eu era preta... Mas eu não sabia que isso teria um peso na minha formação, né? (Amanda).

A percepção de ser preta e isso ter um peso, apesar de já se reconhecer antes como preta, não se trata de um fortalecimento identitário resultante de sua autoafirmação em seu pertencimento racial, como proposto por Marques (2018), mas da compreensão de que seu pertencimento racial a retira da condição de pertencimento ao contexto de formação em Psicologia, conforme apontado por Pinto e Ferreira (2014, p. 262):

Ao negro sempre recai um olhar que lembra que ele é negro, isto é, o fato de ser negro nunca é esquecido e todas as suas inúmeras outras características são postas de lado diante da lembrança de sua pertença racial. Ele é, antes de tudo, negro. Qualquer coisa que faça está vigiada pelo fato de ser negro. Isso não acontece com o branco. Como padrão de normalidade, sua identidade não é questionada.

Reconhecer-se como minoria em um espaço e até mesmo não se reconhecer na ciência discutida em questão, a Psicologia, foi um discurso recorrente na fala das estudantes:

O fato de você não se sentir pertencente naquele ambiente é... como se todos os momentos ali, é... Te fizessem desistir, sabe?... Estar ali na instituição é meio que um ato de resistência diário, é bem complicado porque você não se reconhece e o fato de eu estar no nono periodo, eu olho assim para trás, pros meus primeiros periodos e eu penso assim: "O que eu tô fazendo aqui, sabe?". Eu tenho feito um ato de resgate mesmo e esse processo do curso, do que eu aprendi, de como foi esse processo pra mim e eu fico assim pensando do quanto que eu não me reconheço ali dentro, do quanto esse curso, ele não me representa, sabe? (Rita). 
No próximo relato, a entrevistada que está no final da graduação faz uma retrospectiva no curso e é possível perceber como a ausência de representatividade foi marcante em sua trajetória, de como foi uma lacuna.

Porque se a gente disser que essa Psicologia aí, que ela está sendo feita, ela é aplicada para pessoas brancas, mas ela não é aplicada para pessoas negras, a gente está dizendo que a formação que a gente tem em Psicologia no Brasil é praticamente inútil. Porque mais da metade da população vai ser beneficiada pelo desenvolvimento da Psicologia é a população que não está dentro dessa generalização que a gente estuda. (Isabela).

Assim, a primeira barreira que parece se evidenciar é a da não percepção de pertencimento das mulheres negras ao contexto da graduação em Psicologia. Isso se dá tanto porque não percebem que pertencem ao ambiente, como Rita, ou porque acreditam que a população negra não poderá se beneficiar do que está aprendendo em um curso que forma para atender pessoas brancas, pela percepção de Isabela. Então, a mensagem que recebem é de que aquele espaço não é para elas e a profissão que escolheram também não é pensada para beneficiar pessoas como elas.

\section{Questão financeira}

Como vimos, a diferença salarial entre mulheres negras a brancas chega a 37,5\%, mesmo quando a mulher negra tem as mesmas características de formação que outras mulheres (SÃO PAULO, 2014). Este recorte relacionado ao reconhecimento pelo trabalho parece estar presente em todas as esferas e alimentar um ciclo vicioso que coloca a mulher negra em permanente condição de desvantagem em relação aos homens e a outras mulheres. Concordando com Almeida (2018a), o discurso da meritocracia se apoia na ideologia da democracia racial e na negação do racismo estrutural. Então, a garantia de entrada na universidade é uma das barreiras a ser enfrentada pela mulher negra. A permanência, no entanto, não depende exclusivamente de seu esforço ou da motivação interna para a conclusão do curso, há aspectos materiais que não podem ser desconsiderados.

\begin{abstract}
É... a gente entra na universidade, nós população negra, a gente vai entendendo que, além de pensar que estar lá é uma conquista, a gente vai pensar no outro processo de permanência. Então não basta ter políticas afirmativas que me coloquem lá, tem que pensar na minha permanência da minha formação. (Amanda).
\end{abstract}

Amanda enfatiza um aspecto importante que é a permanência dessas estudantes na graduação, pois apenas garantir a sua presença não faz com o que elas se sintam pertencentes àquele espaço. Podemos retomar aqui os alertas feitos por Bordieux e Champagne (2001), sobre os excluídos do interior, ou seja, aqueles estudantes que ficam excluídos mesmo quando mantidos no curso, pois são "marginalizados por dentro" (BOURDIEU; CHAMPAGNE, 2001, p. 485). Há fatores financeiros que impactam a permanência das estudantes, que estão relacionados inclusive à sobrevivência (delas mesmas e de seus familiares, em muitos casos). Aquelas que participaram da pesquisa são as que conseguiram se manter até o momento da coleta, mas parece haver um custo alto e o resultado pode ser a evasão ou até mesmo o aumento da precariedade financeira e da qualidade de vida de quem decide se manter no curso, como aparece na fala de outra entrevistada:

Eu era bolsista Prouni mas não 100\%, 50\%. E eu sai do serviço, eu trabalhava e estudava, eu saí do serviço pra poder suprir a pesquisa do TCC, dos estágios e fiquei sem dinheiro pra pagar, eu tive que depender da minha mãe que me ajudou financeiramente nessa questão. E até hoje eu estou desempregada. (Nicole).

\section{Questão racial}

Como um dos pontos cruciais deste artigo, a questão racial será tratada em três enquadres: a questão racial na formação em Psicologia; a questão racial e a instituição acadêmica e a 
representatividade de autoras e professoras negras. Cabe aqui o apontamento do quanto a formação em Psicologia está se ausentando no não cuidado à estudante negra quando esta não pode ser abordada de forma mais enfática no ambiente universitário. As falas abaixo evidenciam esta questão:

É um desconforto quando se fala em questões raciais na Psicologia. (Maria).

A faculdade quase não tinha discussões sobre isso, todas as discussões de que eu participei foram sempre por um movimento muito individual de alguém que foi atrás e que conseguiu trazer isso pra turma quanto pra universidade; quando esse espaço existia, ele era muito mínimo. (Carolina).

O problema que a gente tem na formação em Psicologia em relação às questões de negritude e da mulher negra é que, como todos os espaços de formação, seja na educação básica, seja na educação superior, a nossa história é apagada. (Isabela).

De acordo com as constatações de Almeida (2018b), podemos refletir sobre o quanto o tema raça, mesmo quando não discutido em salas de aulas dos cursos de Psicologia, colabora para a manutenção do racismo:

O racismo é uma forma de discriminação que leva em conta a raça como fundamento de práticas que culminam em desvantagens ou privilégios para indivíduos, dependendo do grupo racial ao qual pertençam. O racismo, que se materializa como discriminação racial, caracteriza-se pelo seu caráter sistêmico e, desse modo, não pode ser definido como um ato ou conjunto de atos, mas como um processo em que as condições de subalternidade de um grupo racial e, por outro lado, de privilégios de outro, encontram condições de reprodução nos âmbitos da política, da economia e das relações cotidianas. (ALMEIDA, 2018b, p. 82).

Vemos a necessidade desse debate dentro dos cursos, que por vezes é encarado como uma situação extrauniversidade, quando uma das entrevistadas aponta que apesar de toda sua formação, o racismo virá à frente disso:
Enquanto a gente for uma sociedade racista, eu vou ter cara de empregada doméstica. Não importa quantos idiomas eu fale, não importa quantas habilidades eu tenha e qual seja a minha competência. (Isabela).

\section{Universidade e temática racial}

Apesar de, como visto, a temática racial ser calada e desqualificada por docentes e discentes, o preconceito racial é trazido no contexto universitário nas falas e nas atitudes, de forma naturalizada.

Uma professora estava na aula falando sobre a história da vida dela. Enfim, ao contar sobre a história da vida dela se referiu a uma pessoa como 'carvãozinho' ela se virou, se referiu a essa pessoa como 'carvãozinho' ainda fez um gesto na pele, esfregando na pele como 'carvãozinho'. (Rita).

É tipo como: Ah, você faz Psicologia, ah que legal'. Você não parece que faz Psicologia'. É como se não, nós não temos a cara da Psicologia. Que realmente não temos, porque se você for olhar, o contexto, a maioria é branca. (Daniela).

A Isabela não vai falar sobre Psicologia para família, que é o que ela pesquisa; a Isabela não vai falar sobre Psicologia para mães, que é o que ela pesquisa; ela vai falar sobre racismo. Não é só sobre isso que pessoas negras falam, independente da formação delas? (Isabela).

O quanto os brancos estão realmente interessados em ouvir? Por que é que só nós negros temos que ouvir sobre a violência que os negros sofrem? (Heloísa).

A problematização necessária à abordagem da temática racial não está presente com consistência na formação e as participantes da pesquisa evidenciam as considerações trazidas por Schucman (2018) de que os currículos dos cursos de Psicologia não trazem referências aos temas de raça e do racismo e de que a formação desconsidera as diferenças da categoria raça como fator importante na constituição do psiquismo humano. Além disso, as entrevistadas sequer mencionam terem tido contato, em sua formação, com conhecimentos de 
tradições e saberes da ancestralidade dos povos negros, que seria, como destaca Santos (2019), importante para ressignificar a formação do psicólogo, de modo a recriar as bases epistemológicas para a Psicologia no Brasil.

\section{Representatividade de professoras(es)/ autoras(es) negras(os)}

Concordamos com Khoury e Castelar (2016), quando afirmam que a representatividade da população negra nas profissões se dará pelo ingresso desta no ensino superior. No entanto, entre o ingresso e a conclusão existe toda a formação que ocorre, como vimos, com a quase total ausência de professoras(es) e autoras(es) negros de referência à estudante de Psicologia. Esta situação, que já havia sido evidenciada nas respostas ao questionário também se destacou, como incômodo, nas entrevistas.

Cadê os professores negros? Eles não existem? Eles existem e eu quero saber por que é que a gente não tem professores negros. Eles não são qualificados? Eles não estão enviando currículos? O que é que está acontecendo? (Amanda).

Só tive uma, uma única professora, chegou meio que no último semestre e fez a gente parar para entender que não é uma profissão por assim dizer, de negros. (Carolina).

Eu tinha uma única professora que era professora substituta, então ela ficou quatro anos e agora ela não... Saiu esse semestre, então agora eu não tenho mais nenhum professor negro. (Daniela).

Nossa formação de Psicologia hoje é muito voltada ainda para um público de elite né? E o que é pregado lá, pelo menos onde eu estudei é aquela psicanálise europeia lá e tal... Do Freud, Lacan e Winnicott. E aí, no último ano da faculdade, eu vou descobrir que existe Fanon, que existe Neuza Santos, Isildinha e tantas outras coisas que poderiam ser diferentes né? (Nicole).

Dentro das matérias de Psicologia, eu tive um [autor negro], foi o Fanon, foi a única experiência também que a gente teve trazida por professor, porque às vezes rola a tentativa de você levar pra dentro da sala de aula, mais de estar nas referências bibliográficas, dentro do curso de Psicologia, só uma experiência em quatro anos. (Fernanda).

Santos (2019) defende a inclusão da perspectiva do que ele denomina como "enegrecimento" na formação do psicólogo, que se dará a partir da construção, de forma coletiva, da equidade social e racial de participação na produção e transmissão dos saberes psicológicos.

\section{A questão pessoal}

Para o debate dos fatores que permeiam a resistência (re-existência) das mulheres negras e os espaços em que elas ocupam, faz-se necessário dar maior voz às mesmas. A Psicologia, como ciência que está presente na sociedade, precisa discutir essa questão, não como direcionamento das atuações dos psicólogos e sim como parte da Psicologia, como parte do fazer a Psicologia, desde a sua formação até a atuação.

Além da identidade atribuída pelo outro (professores, alunos, usuários dos serviços de Psicologia) é importante verificar como esta identidade é assumida pela estudante negra. A constituição da identidade negra pode ser considerada uma tarefa política para a qual, nos dizeres de Sousa (1983), é necessário ser contestado o modelo incorporado que transforma o sujeito em uma caricatura do branco. As condições para perceber a própria imagem requer o rompimento com esse modelo, o que não é simples, como vemos nos relatos a seguir:

O paciente não te enxerga, eu já vi relatos, vários, o paciente pensar que você é a faxineira porque ele não te encara como profissional, tem mais essa barreira, não é só se formar, não é só querer. (Laura).

Eu consegui me perceber negra, no quarto ano de universidade, quando a questão foi levantada porque, assim, caramba, agora eu parei pra perceber que eu realmente sou uma pessoa negra e eu nunca tinha parado pra pensar, 
todas as questões de preconceitos encobertos que ocorreram no dia a dia, eu nunca tinha parado pra pensar sobre isso. (Carolina).

Isso tem efeitos sobre a percepção de pertencimento da estudante no curso sobre o sofrimento produzido nessa vivência, como evidenciado a seguir:

Não é tão feliz assim, eu não vou sentir tanta saudade assim porque foi um período muito sofrido. Tipo, foi bom, foi muito importante estar na universidade pública, incrivel assim, a (nome da universidade) é muito boa. É uma referência pro Estado né? Só que, tipo não foi, não foi tão delicioso assim como a maioria tava colando sabe? (Heloísa).

\section{Considerações finais}

A busca de um lugar de fala durante a graduação foi uma das inquietudes de uma das autoras da seguinte pesquisa, que é uma mulher negra e estudante de Psicologia na ocasião da elaboração da pesquisa. Assim, observou-se que ter esta condição para pesquisar sobre as barreiras enfrentadas por outras mulheres negras em sua formação acadêmica pôde proporcionar um encontro de identificações e de trajetórias o que, de fato, pareceu ter facilitado o diálogo nas entrevistas e a compreensão dos resultados. Por vezes, no entanto, houve a dúvida de se a pesquisa poderia responder somente a uma angústia pessoal desta pesquisadora e de ser - como muitas vezes dizem sobre denúncias de racismo - "coisa de sua cabeça" e isso configurar uma mistura que tornasse inviável a continuidade do trabalho ou não aceitáveis os resultados.

Concordamos com Ribeiro (2017), no que diz do entendimento do lugar de fala, não somente como um espaço de fala em si, mas do lugar de fala carregado de experiências sociais que atravessam os sujeitos e que determinam quais são os lugares que eles podem ocupar e como devem ocupar, sendo esse questionamento primordial quanto ao momento de como devemos dizer determinado fato, afinal como poderia uma pessoa branca falar da dor de uma pessoa negra sendo que as situações que vivenciam não são semelhantes? Diante disso, a orientadora da pesquisa e coautora do presente artigo, também mulher, mas, branca e professora de Psicologia, vivenciava o desafio de acompanhar o processo de pesquisa e servir como interlocutora, sem, ao mesmo tempo, ocupar o lugar de fala de sua orientanda e sem encobrir as possíveis feridas escancaradas e incômodas que se desvelavam. O questionamento quanto à cor da orientadora da pesquisa surgiu como indagações por algumas das participantes das entrevistas. Essa dúvida pareceu vir acompanhada justamente disso, desse lugar de escuta, desse estranhamento ou até mesmo de resistências que podem ser suscitadas pela abordagem, no contexto nas relações acadêmicas, dos temas raciais, por pessoas brancas.

$\mathrm{O}$ contato com tais questionamentos mobilizou a reflexão sobre interferências verticais e de poder que poderiam se reproduzir na relação entre professora orientadora branca e estudante negra de Psicologia. A construção do trabalho implicou essa revisão dos lugares: de fala, da escuta e de acolhimento mútuo.

Um dos resultados das tensões provocadas pelas diferenças explícitas entre orientadora e estudante pesquisadora foi o esforço para abertura de ambos os lados em direção à aproximação aos fenômenos percebidos, que possibilitou aprendizado sobre as diferentes condições das participantes, que traziam tanto estranhamentos quanto identificações. Isso se deu por meio do diálogo constante, da possibilidade de reconhecimento das diferenças entre as experiências e pelo respeito conquistado no enfrentamento dos novos conhecimentos e questionamentos que se apresentavam.

Outra decisão também tomada foi a de garantir o protagonismo e a voz da pesquisadora negra, permitindo que suas experiências durante a formação pudessem ajudar a ler os fenômenos identificados nas participantes da pesquisa. A angústia sobre o não falado em sala de aula durante toda a formação e a forma de não se sentir pertencente à ciência discutida em questão, foram os disparadores para muitas indagações e para algumas das articulações com o material coletado. 
Uma terceira decisão importante no processo partiu da percepção de que a leitura dos artigos, o contato que vinha sendo feito com os resultados obtidos e a leitura possível apresentada pela orientadora não pareciam ser suficientes para ajudar a nomear as tantas sensações pessoais vivenciadas ao longo do processo e as inúmeras barreiras enfrentadas. Foi necessária, então, a busca por uma bagagem complementar à universidade, pelo ingresso da pesquisadora que era estudante de Psicologia no curso "Psicologia e Relações Raciais", do Instituto Amma Psique e Negritude, em São Paulo. Cabe aqui enfatizar que é um curso teóricovivencial no qual os participantes do processo mergulham na experiência de estudar as relações raciais, por uma ampla abrangência ao tema, incluindo: o conceito de raça; a constituição do sujeito branco e seus privilégios; a subjetividade do negro permeado pelo racismo e como o corpo é marcado pelas vivências das relações raciais. Lá, ocorreu algo fundamental: o encontro da estudante com outras mulheres, psicólogas e pesquisadoras de diferentes áreas, também negras, o que permitiu a nomeação e o encontro de ressonâncias de sensações e ideias, que puderam se constituir como articulações que seriam incorporadas à pesquisa.

Os resultados obtidos proporcionaram um panorama expressivo sobre questões impeditivas que cercam a formação da psicóloga negra e poderão fornecer aos estudantes e docentes de Psicologia elementos para reflexão sobre barreiras que devem ser identificadas na formação profissional, contribuindo para ações e estudos relativos à formação $\mathrm{da}(\mathrm{o})$ psicóloga(o).

Ficou evidenciado que, apesar das ações envolvidas em relação à temática nos últimos anos, é necessário o maior aprofundamento e debate para que as mulheres negras possam ter mais destaque no espaço acadêmico e consequentemente na área. No entanto, foi muito dolorida a percepção de que elementos descritos no artigo "Eu, mulher, negra e psicóloga", de 1984, estão muito presentes nos relatos das participantes deste estudo, mesmo após três décadas de sua publicação. Assim, foi visto que as mulheres negras ainda enfrentam entraves na sua formação por simplesmente serem pessoas negras. Perceber que um estereótipo chega à frente de qualquer formação, enquadrando indivíduos em rótulos é muito difícil. Ao mesmo tempo, ameniza essa dor saber que têm mulheres negras e pessoas associadas à luta antirracismo na caminhada para a erradicação e enfrentamento da realidade que se apresenta.

Ao conhecer as barreiras evidenciadas neste estudo, ações efetivas podem ser realizadas. Por exemplo, propõe-se aos representantes e responsáveis pelas instituições de ensino de Psicologia que atentem para o número de docentes presentes no quadro de profissionais e para o número de estudantes negros nas turmas de psicologia. Que a construção dos currículos dos cursos considere a realidade de constituição do povo brasileiro e suas diversas heranças culturais, em especial as de matriz africana. Além disso, é importante que seja estimulado o debate da questão racial não somente quando trazida por alunos, mas sim como iniciativa da própria instituição, num esforço contínuo, pela criação de espaços de discussão e enfrentamento da questão e não se limitando ao 20 de novembro, conhecido como o "Dia da Consciência Negra".

No que se refere à sugestão de novos estudos, os resultados aqui obtidos apontam que, apesar de muito consistentes as reflexões proporcionadas pelo processo, há ainda muitas vozes a serem escutadas e que podem trazer luz a questões não exploradas. Por exemplo, houve, durante a elaboração desta pesquisa, o contato com declarações de psicólogas negras, (portanto já graduadas e que não puderam participar desta pesquisa), as quais manifestaram o desejo de narrar suas trajetórias no período da graduação. Escutar seus relatos pode ser um caminho de aprofundamento sobre a temática, de forma a investigar se as barreiras descritas neste artigo também estiveram presentes na formação destas mulheres e se ainda são questões que as acompanham no desenvolvimento profissional.

Como o tema merece diferentes estratégias de aprofundamento, outras metodologias de pesquisa podem ser realizadas no futuro, como, por exemplo, a realização de grupos focais com alguns 
dos temas elencados aqui, que poderiam incluir estudantes, professores e coordenadores de cursos de Psicologia. A possibilidade de explorar como as professoras negras da área encaram as vivências das relações raciais, pode ser um importante dado para o contato com a visão de alguém que já passou pela graduação e agora se constitui como modelo e figura de representatividade para outras mulheres negras em formação na área e este poderia também ser um interessante tema de pesquisa. E, como forma de analisar o quanto essa profissão é vista no imaginário de estudantes, outra proposta de intervenção ou estudo, poderia se dar pelo estudo com alunas do ensino médio, investigando quais seriam as profissões / cursos que pretenderiam escolher para verificar se a Psicologia constaria nas opções pretendidas.

Os resultados da pesquisa aqui apresentada confirmam que a formação da mulher negra em Psicologia é, sim, atravessada por muitas barreiras, mas a principal parece ser a do isolamento e da sensação de não poder pertencer, de não poder se encaixar e de, portanto, estar só. Outras barreiras, no entanto, são as questões de gênero, raça e classe que, apesar de serem enfrentadas de forma separada por mulheres brancas e homens (brancos e negros), estão muito associadas na experiência da estudante negra.

Por isso, as autoras deste artigo querem direcionar um recado às mulheres negras que estudam ou pretendem estudar Psicologia: você mulher, negra e estudante de Psicologia, onde quer que esteja ou estude, saiba, você não está sozinha, essa angústia não é somente sua. A sua trajetória é importante e sua singularidade merece ser respeitada, suas aflições merecem ser discutidas e precisam e podem ser inseridas no cotidiano dos cursos de Psicologia, pois a Psicologia precisa reconhecer a especificidade de ser mulher e negra no Brasil e isso será cada vez mais possível com a sua participação ativa nesse processo. Mas, é importante também enviar um recado às outras pessoas que fazem parte dos contextos de formação em psicologia: as barreiras enfrentadas pelas mulheres negras na formação não podem ser naturalizadas e não é justo que se espere que sejam rompidas, de forma heroica, por elas. Então, cabe a todos os envolvidos no processo, mas principalmente, aqueles que não as enfrentam, o esforço para a identificação e eliminação de quaisquer barreiras que possam se interpor na formação de mulheres negras em Psicologia.

\section{Referências}

ALMEIDA, S. L. Estado e direito: a construção de raça. In: SILVA, M. L.; FARIAS, M.; OCARIZ, M. C.; STIEL NETO, A. (Org.). Violência e sociedade: o racismo como estruturante da sociedade e da subjetividade do povo brasileiro. São Paulo: Escuta, 2018b. p. 81-96.

ALMEIDA, S. L. O que é racismo estrutural? Belo Horizonte: Letramento, 2018a.

BORSEZI, C. S.; BORTOLOMASI, E.; LIBONI, R. G.; REIS, M. F.; TAMANAHA, H. Y.; GUIMARAES, J. L. Representação social da psicologia e do psicólogo sob o olhar da comunidade de Assis/SP - Brasil. Psicologia para América Latina, México, n. 14, out. 2008. Disponível em: https://bit.ly/3rRTtIP. Acesso em: 8 jul. 2020.

BOURDIEU, P.; CHAMPAGNE, P. Os excluídos do interior. In: BOURDIEU et al. (Org.). A miséria do mundo. 4. ed. Petrópolis: Vozes, 2001.

BRANDAO, A. A. Rompendo barreiras educacionais: negros no ensino superior. Physis: Revista de Saúde Coletiva, Rio de Janeiro, v. 14, n. 1, p. 163-167, jun. 2004. Doi: https://doi.org/10.1590/ S0103-73312004000100011. Disponível em: https://bit.ly/31PnLRU. Acesso em: 21 jun. 2020.

BRASIL. Ministério da Educação. Lei no 13.146, de 6 de julho de 2015. Institui a Lei Brasileira de Inclusão da Pessoa com Deficiência (Estatuto da Pessoa com Deficiência). Diário Oficial da República Federativa do Brasil, Brasília, DF, 7 jun. 2015. Disponível em: https://bit.ly/31RdyUI. Acesso em: 21 jun. 2020.

BRASIL. Ministério da Educação. Resolução N ${ }^{\circ}$ 466, de 12 de dezembro de 2012. Trata de pesquisas em seres humanos e atualiza a resolução 196. Diário Oficial da República Federativa do Brasil, Brasília: DF, 2013. 
BRASIL. Ministério da Educação. Resolução $n^{\circ} 5$, de 15 de março de 2011. Institui as Diretrizes Curriculares Nacionais para os cursos de graduação em Psicologia, estabelecendo normas para o projeto pedagógico complementar para a Formação de Professores de Psicologia. Brasília, DF: Ministério da Educação, 2011. Disponível em: https://bit. 1y/31KpOXc. Acesso em: 24 jun. 2020.

BRASIL. Ministério da Educação. Revisão das Diretrizes Curriculares Nacionais (DCNs) dos Cursos de Graduação em Psicologia e estabelecimento de normas para o Projeto Pedagógico Complementar (PPC) para a Formação de Professores de Psicologia. Brasília: Ministério da Educação, 2020. Disponível em: https://bit.ly/39IEJWl. Acesso em: 2 jun. 2020.

CARMO, M. C. O papel dos afetos no processo de formação de psicólogos. 2011. Dissertação (Mestrado em Psicologia) - Pontifícia Universidade Católica de Campinas, Campinas, 2011.

CARNEIRO, S. Enegrecer o feminismo: a situação da mulher negra na América Latina a partir de uma perspectiva de gênero. In: ASHOKA EMPREENDIMENTOS SOCIAIS; TAKANO CIDADANIA (Org.). Racismos contemporâneos. Rio de Janeiro: Takano Editora, 2003.

CASANOVA, D. G.; POLYDORO, S. Integração ao ensino superior: relações ao longo do primeiro ano de graduação. Psicologia Ensino \& Formação, Brasília, v. 1, n. 2, p. 85-96, 2010.

CONSELHO FEDERAL DE PSICOLOGIA. Código de ética profissional do psicólogo. Brasília: CFP, 2005.

CONSELHO FEDERAL DE PSICOLOGIA. Relações raciais: referências técnicas para atuação de psicólogas/os. Brasília: CFP, 2017.

DEPARTAMENTO INTERSINDICAL DE ESTATÍSTICA E ESTUDOS SOCIOECONÔMICOS. Projeto 2: levantamento de informações sobre a inserção dos psicólogos no mercado de trabalho brasileiro. São Paulo: DIEESE, 2016.

EU, mulher negra e psicóloga. Psicologia: Ciência e Profissão, Brasília, DF, v. 4, n. 2, p. 1015, 1984. Doi: https://doi.org/10.1590/S141498931984000200004. Disponível em: https://bit. ly/2RcrtD7. Acesso em: 21 abr. 2020.
GIL, A. C. O psicólogo e sua ideologia. Psicologia: Ciência e Profissão, Brasília, DF, v. 5, n. 1, p. 1217, 1985. Doi: https://doi.org/10.1590/S141498931985000100005. Disponível em: https://bit. ly/3cSqUXg. Acesso em: 8 jul. 2020.

GLASS, R. D. Entendendo raça e racismo: por uma educação racialmente crítica e antirracista. Revista Brasileira de Estudos Pedagógicos, Brasília, DF, v. 93, n. 235, p. 883-913, dez. 2012. Doi: https:// doi.org/10.1590/S2176-66812012000400017. Disponível em: https://bit.ly/3t4Dbhb. Acesso em: 16 jun. 2020.

HOLANDA, M. A. G.; WELLER, W. Trajetórias de vida de jovens negras da Universidade de Brasília no contexto das ações afirmativas. Poiésis, Florianópolis, v. 8, n. 13, p. 57-80, 2014. Disponível em: https://bit.ly/31L21X1. Acesso em: 21 jun. 2020 .

HOOKS, B. Olhares negros: raça e representação. São Paulo: Elefante, 2019.

KHOURI, J. G. R.; CASTELAR, M. Percepções de estudantes sobre o debate das relações raciais na formação em psicologia. Psicologia Ensino \& Formação, São Paulo, v. 7, n. 2, p. 53-62, 2016. Disponível em: https://bit.ly/39G6ONN. Acesso em: 21 abr. 2020.

MÄDER, B. J. (Org.). Caderno de psicologia e relações étnico-raciais: diálogos sobre o sofrimento psíquico causado pelo racismo. Curitiba: CRPPR, 2016.

MARIANA, M. M.; PINHEIRO, L.; QUEIROZ, C.; QUERINO, A. C.; VALVERDE, D. Dossiê mulheres negras: retrato das condições de vida das mulheres negras no Brasil. Brasília: Ipea, 2013.

MARQUES, E. P. S. O acesso à educação superior e o fortalecimento da identidade negra. Revista Brasileira de Educação, Rio de Janeiro, v. 23, e230098, 2018. Doi: https://doi.org/10.1590/ s1413-24782018230098. Disponível em: https:// bit.ly/3dBciuv. Acesso em: 21 abr. 2020.

MINAYO, M. C. S. O desafio do conhecimento: pesquisa qualitativa em saúde. 11. ed. São Paulo: Hucitec, 2008.

MUNANGA, K. As ambiguidades do racismo à brasileira. In: KON, N. M.; ABUD, C. C.; 
SILVA, M. L. (Org.). O racismo e o negro no Brasil: questões para a psicanálise. São Paulo: Perspectiva, 2017. p. 33-44.

MUNANGA, K. Considerações sobre as Políticas de Ação Afirmativa no Ensino Superior. In: PACHECO, J. Q.; SILVA, M. N. (Org.). O negro na universidade: o direito à inclusão. Brasília, DF: Fundação Cultural Palmares, 2007. p. 7-22.

PINTO, M. C. C.; FERREIRA, R. F. Relações raciais no Brasil e a construção da identidade da pessoa negra. Pesquisas e Práticas Psicossociais, São João del-Rei, v. 9, n. 2, p. 257-266, dez. 2014. Disponível em: https://bit.ly/3sTu171. Acesso em: 12 jul. 2020.

PIRES, L. H. S. Formação do psicólogo: perspectivas de alunos de um curso de graduação. 2008. Dissertação (Mestrado em Psicologia) Universidade de São Paulo, Ribeirão Preto, 2008.

RIBEIRO, D. O que é: lugar de fala? Belo Horizonte, MG: Letramento, 2017.

RIBEIRO, M. E.; SOLIGO, Â. F. Diretrizes Curriculares e Formação do Psicólogo Brasileiro: avanços, retrocessos e desafios. Revista Integración Académica en Psicología, Ciudad de México, v. 8, n. 22, p. 36-49, 2020.

SANTOS, A. O. O enegrecimento da psicologia: indicações para a formação profissional. Psicologia: Ciência e Profissão, Brasília, v. 39, n. spe, e222113, p. 159-171, 2019. Doi: https://dx.doi. org/10.1590/1982-3703003222113. Disponível em: https://bit.ly/3sRWutD. Acesso em: 21 abr. 2020 .

SANTOS, G. G.; SILVA, L. C. A evasão na educação superior: entre debate social e objeto de pesquisa. In: SAMPAIO, S. M. R. (Org.). Observatório da vida estudantil: primeiros estudos Salvador: EDUFBA, 2011. p. 249-262.

SÃO PAULO. Secretaria Municipal de Promoção da Igualdade Racial. Igualdade racial em São Paulo: avanços e desafios. São Paulo: SMPIR, 2014.

SÃO PAULO. Secretaria Municipal de Promoção da Igualdade Racial. Relatório de gestão: políticas de igualdade racial em São Paulo. São Paulo: SMPIR, 2013.
SCHUCMAN, L. V. Branquitude e privilégio: violência e sociedade. In: SILVA, M. L.; FARIAS, M.; OCARIZ, M. C.; STIEL NETO, A. (Org.). $O$ racismo como estruturante da sociedade e da subjetividade do povo brasileiro. São Paulo: Escuta, 2018. p. 137-150.

SOUSA, N. S. Tornar-se negro: as vicissitudes da identidade do negro em ascensão social. Rio de Janeiro: Edições Graal, 1983.

TEIXEIRA, M. P. Negros na universidade: identidade e trajetórias de ascensão social no Rio de Janeiro. Rio de Janeiro: Pallas, 2003.

VANNUCHI, M. B. C. C. A violência nossa de cada dia: o racismo à brasileira. In: KON, N. M.; ABUD, C. C.; SILVA, M. L. (Org.). O racismo e o negro no Brasil: questões para a psicanálise. São Paulo: Perspectiva, 2017. p. 59-70.
Recebido em: 22 abr. 2020

Aceito em: 23 jul. 2020 
Santos, A. S. R.; Emílio, S. A. 